\title{
Mono Nanofluids: Review on Current Status, Challenges and Future Prospects
}

\author{
Ibeh, Stanley .C ${ }^{1}$, M. B. Ndaliman ${ }^{1,2}$, Ugwoha Ezedimbu ${ }^{3}$, James Audu ${ }^{4}$, Okoro C. Anthony ${ }^{5}$, Emeka Osther ${ }^{6}$, \\ Abdulganiyu .L. Yusuf ${ }^{7}$, Ugwu .C. Lawrence $^{8}$, Attahiru Illiyasu ${ }^{9}$ \\ 1,3,4,5,6,7,8,9 Scientific Equipment Development Institute, Minna-Niger State, Nigeria \\ ${ }^{2}$ Federal University of Technology, Minna-Niger State, Nigeria \\ DOI: https://dx.doi.org/10.51584/IJRIAS.2021.6302
}

\begin{abstract}
Advancement in the area of technology, industrial application demands effective, efficient and successful heat transfer application. Nanofluids are proven potential heat transfer fluids with heighten thermo physical properties and heat transfer performance. In this paper, a comprehensive review on the current status, applications and challenges associated with the use of nanofluids have been evaluated and presented in the study. Authors also critically examined and identified research gaps for further research directions. The comprehensive study and assessment are essential to be carried out to ensure maxima utilization of nanofluid as new and potential heat transfer fluid.
\end{abstract}

Keywords: nanofluid, thermal conductivity, nanofluid stability, heat transfer

\section{INTRODUCTION}

$\mathrm{T}$ he recent decades have shown an unprecedented growth in various technologies such as communication, computing, transportation and electronics, and there is possibilities it's continue to be unabated in the present century. The progressive growth of these technologies and their respective devices in a reduced scale or sizes, an enhanced rate of functionalities and data storage has brought about serious challenges to thermally manage these miniature devices. The increasing functions and power of these devices with corresponding decreasing size simply call to mind the need for an innovative cooling technology. The advent of Micro-Electro-Mechanical Systems (MEMS) and nanotechnology has not only intensified this need but also calls for a revolution in cooling and heat treatment technology and to keep pace with the recent revolution in device technology. However, it is imperative to note that large devices (such as in transportation trucks) and fuel energy cells (such as electrochemical devices) also requires efficient cooling systems with greater cooling capacities and decreased sizes [1].

Generally, solid particles possess higher conductive ability than common heat transfer liquids. Dispensing solid particles in liquid consequently enhances the cooling potential of the liquid by increasing the thermal conductivity of the suspended fluid. In achieving higher thermal conductivity in the past, relatively large ("milli" or "micro" scale) particles were employed. These fluids produce the required cooling results but their implementation is complicated by their likelihood in damaging sensitive mechanical parts such as pumps and valves by clogging fluid flow passages due to settling of particles. Recent developments in nanotechnology and related manufacturing algorithms have made the production of far smaller - nanosized particles possible. Such particles in greater extent reduce the damage to flow loop components while at the same time provide better cooling benefits. The name nanoparticle implies solid particles with size ranging from $1-100 \mathrm{~nm}$ is refer to as nanoparticle, when such solid nanoparticles are dispersed in a based-fluid with the sole aim of increasing thermal conductivities of heat transfer fluids is refer to as 'nanofluids'.

Some typical traditional liquids used as base fluids are water, ethylene glycol (EG), refrigerants and engine oil. Nanoparticles can be mixed with different base fluids in different concentration ratio. Hence, Enhancement of thermal performance of heat pipe using nanoparticles mainly depends upon parameters such as type, size, shape and concentration of nanoparticles and base fluid [2]. These nano-particles/nanoadditives and are subdivided into three basic groups: metallic, oxide, nitrides, carbides and carbon as shown in Figure 1.

Nanofluids possess the following advantages [2];

i. High specific surface area between particles and fluids.

ii. High dispersion stability with predominant Brownian motion of particles.

iii. Reduced pumping power as compared to pure liquid to achieve equivalent heat transfer intensification.

iv. Reduced particle clogging, thus promoting system miniaturization.

v. Adjustable properties, including thermal conductivity and rheological behaviour.

Many outstanding and significant properties using nanofluids have been reported in the past decades. This paper presents an overview of the chronology of nanofluids, recent developments in the study of nanofluids, methods of production, the evaluation approaches in nanofluids stability, means of enhancing their stability, the stability mechanisms, and their potential applications. 


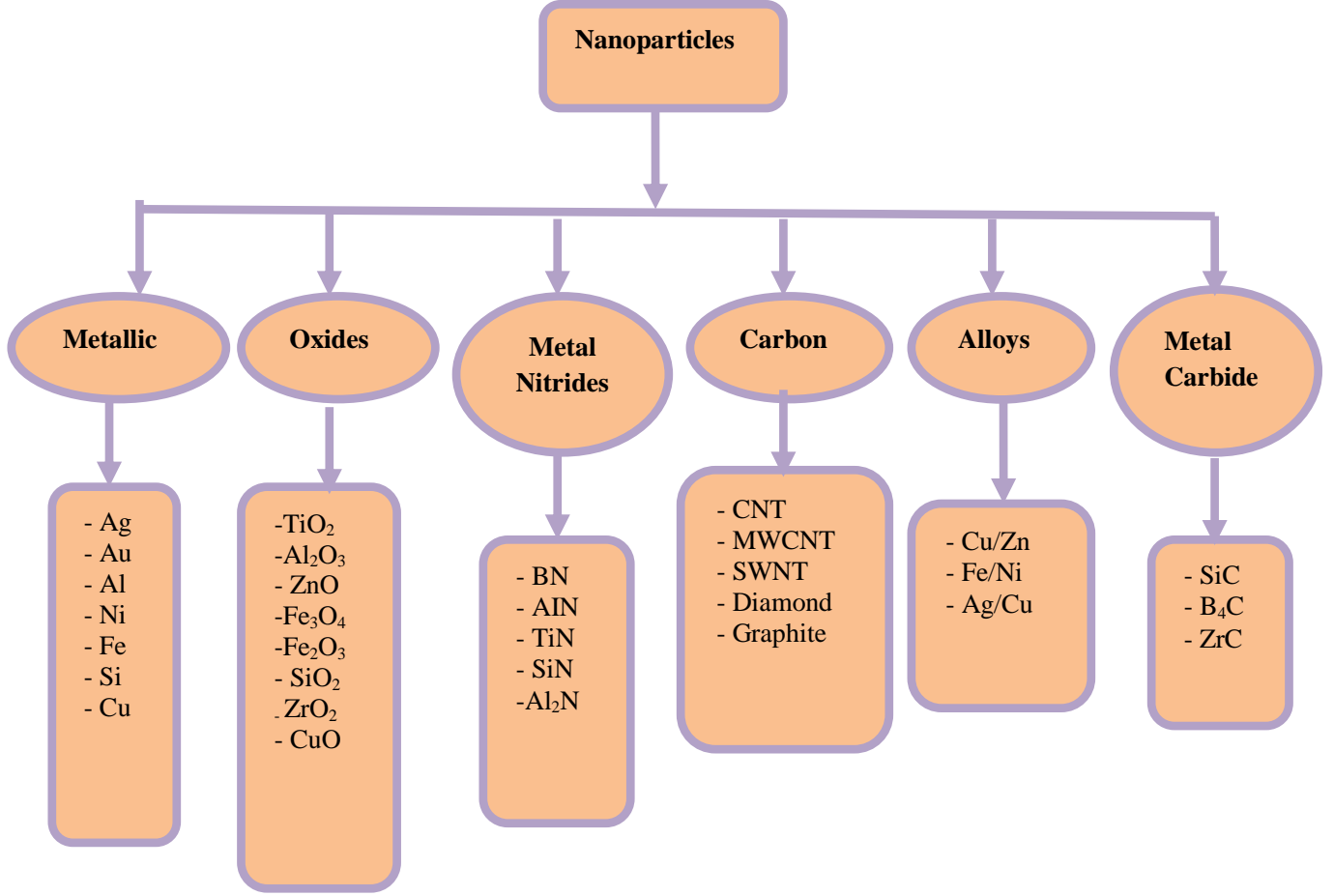

Figure 1. Types of nanoparticles commonly used to prepare nanofluids

\section{CHRONOLOGICAL DEVELOPMENT OF NANOPARTICLES}

Fluids currently used in industrial and thermal settings are often modified with different types of additives with the sole aim of achieving better rheological and thermodynamic properties [3]. However, the origin of nanotechnology and nanoscience abstraction can be traced as far back to 1959 , when an American Nobel laureate-Richard

Feynman - proposed a new theory of quantum electrodynamics. Norio Taniguchi, who presented the basic concept of 'nano-technology' in 1974 during the International Conference on Production Engineering in Japan is also thought to be a pioneer of nanotechnology as a science $[3,4]$. The chronological development of the nanotechnology is summarized in Table 1.

Table 1. some significant historical events of nanoparticles and nanofluids in heat transfer applications

\begin{tabular}{|c|c|}
\hline Year & Findings \\
\hline 1873 & $\begin{array}{c}\text { Maxwell [5] proposes the innovative idea of adding solid } \\
\text { particles to heat transfer fluids to rise their thermal } \\
\text { conductivity thermodynamic parameter. }\end{array}$ \\
\hline 1881 & $\begin{array}{c}\text { Maxwell published academic and experimental papers of } \\
\text { the effective thermal conductivity of dispersions with } \\
\text { millimetre and micro meter-sized solid particles. }\end{array}$ \\
\hline 1951 & Development of ferro-fluids as intelligent nanofluids [6] \\
\hline 1959 & $\begin{array}{c}\text { Richard Feynman proposes a new theory of quantum } \\
\text { electrodynamics and the technical directions of } \\
\text { nanoscience were defined. }\end{array}$ \\
\hline 1974 & $\begin{array}{c}\text { Norio Taniguchi presents in Japan the basic concept of } \\
\text { 'nanotechnology'. }\end{array}$ \\
\hline 1978 & $\begin{array}{c}\text { Suggestions to produce nano-powders from vapour phase } \\
\text { directly into a flowing low vapour pressure fluid fail due to }\end{array}$ \\
\hline
\end{tabular}

\begin{tabular}{|c|c|}
\hline 1986 & problems in subsequently separating the dry particles [7] \\
\hline $1989-$ & $\begin{array}{c}\text { Drexlers gives the idea of molecular nanotechnology and } \\
\text { claims Feynman theory. }\end{array}$ \\
\hline 1994 & $\begin{array}{c}\text { Advanced fluids for industrial applications-including } \\
\text { researchers from the Argonne National Laboratory. } \\
\text { Development of physical gas-phase condensation or } \\
\text { chemical synthesis techniques for the production of } \\
\text { nanopowders with average particle sizes in the 10 nm range }\end{array}$ \\
\hline $1963-$ & $\begin{array}{c}\text { Development a third technique for nanophase material } \\
\text { generation by condensation of metal vapours during rapid } \\
\text { expansion in a supersonic nozzle [8]. }\end{array}$ \\
\hline 1995 & $\begin{array}{c}\text { Choi and Eastman propose for the first time the practical } \\
\text { use of copper nanoparticles dispersed in water [9]. }\end{array}$ \\
\hline 2000 & $\begin{array}{c}\text { Development of mono and hybrid nanofluids for heat } \\
\text { transfer applications (problems and techniques of } \\
\text { stabilization, coagulation and clustering of multi-sized } \\
\text { nanocomposites, heat transfer models, thermal and } \\
\text { rheological properties upgrading) }\end{array}$ \\
\hline
\end{tabular}

\section{SYNTHESIS AND PREPARATION OF NANOPARTICLES}

The preparation of nanofluids is the first key step to synthesize fluids with improved thermal conductivity and other thermal properties [10,11]. Various methods have been attempted to produce different kinds of nanoparticles and nano suspensions. Wongwises et al. [12] suspended $\mathrm{TiO}_{2}$ nanoparticles in water with a volume loading range of 0.2 to 2 $\%$, and they collected the data at a temperature range of 15 to $35{ }^{\circ} \mathrm{C}$. Hamed et al. [13] prepared nanofluids to optimize energy consumption using models. Nirupama Patra et al. [14] investigated the quenching characteristics of metallic vertical rod of stainless steel (SS316L) with an internal heater in alumina-water base nanofluid at different operating 
conditions. A $0.001 \%$ by volume alumina nanoparticle was employed, rod of $12 \mathrm{~mm}$ diameter and $100 \mathrm{~mm}$ length at temperature ranging from $200{ }^{\circ} \mathrm{C}$ to $250{ }^{\circ} \mathrm{C}$. Results show that HTC (heat transfer coefficient) for nanofluids are more than de-ionized water. Paul et al. [15] prepared $\mathrm{Al}_{2} \mathrm{O}_{3}$ nanoparticles dispersed in water and evaluated the effect of different parameters such as the rate of coolant injected, wall temperature $\left(300-500{ }^{\circ} \mathrm{C}\right)$, and concentration of nanofluids of 0.1 and 0.3 volume $\%$ on the quenching behaviour. Authors affirm that the nanofluids take less time to quench as compared to water. Rate of cooling increases with a corresponding increase in concentration of $\mathrm{Al}_{2} \mathrm{O}_{3}$ particles in the nanofluid. The intensity of heat transfer to the flowing quenchants majorly depends upon the initial surface temperature of the specimen and temperature gradient [16].

S. S. Yahya et al. [17] prepared a carbon nanoparticle dispersed in water as base fluid varied at $0.1,0.3$, and $0.5 \%$ vol. the prepared nanofluids was used to quench an AISI 1045 carbon steel samples, annealed at maximum temperature of $1000{ }^{\circ} \mathrm{C}$. The nanofluid shows stability despite the hydrophobic characteristic of carbon. Caio Carvalho et al. [18] prepared an aqueous nanofluid based on mercaptopropionic acid-coated copper sulfide nanoparticles $\left(\mathrm{Cu}_{2} \mathrm{~S} / \mathrm{MPA}\right)$, synthesized by the chemical reduction method. The nanofluid presented colloidal stability in alkaline medium and an enhancement of $36 \%$ in thermal conductivity for a volumetric fraction of $0.05 \%$. An experimental investigation on the cooling performance of a convective loop over a flat heater was performed using $\mathrm{ZnO}$ nanoparticles in the base fluid (water) enhanced the heat transfer coefficient by $20.1 \%$ [19].

Sarafraz et al. [20] suspended $\mathrm{CuO}$ nanoparticles into water (base fluid) and demonstrated an experiment to evaluate the thermal performance of a cooling loop working with liquid gallium and $\mathrm{CuO} /$ water nanofluid. Results showed that $\mathrm{CuO} /$ water nanofluid presents lower pumping power and can be a better alternative for cooling systems compared to the liquid gallium,

Ghasemi et al. $[19,21]$ investigated the influence of geometry of channel on the thermal performance of a mini-channel CPU cooler and showed that, with an increase in diameter of channel, pressure drop in the heat sink reduces. They optimized the performance of the CPU cooler based on the diameter of the channels. Ghasemi et al. [22] prepared an aqueous $\mathrm{TiO}_{2}$ nanoparticles dispersed in water as base fluid to investigate the convective heat transfer and thermal performance of a heat sink. it was discovered that the thermal resistance of the system decreased, while the heat transfer coefficient (HTC) of the system was higher than that of reported for the base fluid (water). Hassanen et al. [23] prepared a $\mathrm{TiO}_{2} /$ water nanofluids to quench a CK35 steel.

\section{IV.THERMOPHYSICAL PROPERTIES OF NANOFLUIDS}

The thermal properties that directly affect the conduction and convection of nanofluids include thermal conductivity, specific heat capacity (SHC) viscosity and density. A concise thermal property data are required for a heat transfer model. Properties such as SHC and density are often assumed that a weighted arithmetic mean of both base fluid and nanoparticle can provide accurate predictions. However, evaluating thermal properties such as thermal conductivity and viscosity of nanofluids will require experimental approach [24].

\section{A. Thermal conductivity property of nanofluids}

Thermal conductivity of nanofluids is discovered to show some outstanding characteristic for many applications. It is referred to as the ability and capacity of a material to manage or transmit heat adequately. It's the most review transport characteristics in nanofluid with the addition of nanoparticles, as generally assumed that enhancement in heat transfer are primarily due to increase in thermal conductivity [25-27]. A vast numbers of studies (experimental and theoretical research) have shown that the addition of nanoparticles can distinctly improve the thermal conductivity of fluid. Lee $\mathrm{et} \mathrm{al}$. [28] in their study reported that the efficiency of nanofluids was significantly enhanced by rise in temperature and an increase in particle size for thermal conductivity and viscosity evaluation. Similarly, Ueki et al. [29] conducted an appraisal on the thermophysical properties of carbon-based material nanofluids. It was discovered that nanoparticle size, shape and temperature influences the thermal conductivity of nanofluids. In addition both carbon-based materials (carbon nanopowder and carbon black) shows increase in thermal conductivity by $19 \%$ and $7 \%$, respectively. Wongwises et al. [12] argued thermal conductivity ratio decreased when the temperature increased.

Deepak et al. [30] in their research developed a model in order to predict the effect of thermal conductivity of nanofluids on particle size distribution and multi-level homogenization. Lenin et al. [31] reported that the critical concentration for thermal conductivity enhancement varies with the use of various surfactants. This can be due to the differences in the degree of aggregation of the nanoparticles and conformation of the surfactant molecules on the nanoparticle's surface. They added that base fluids with lower thermal conductivity and dielectric constant showed larger enhancement in the thermal conductivity relative to base fluids with higher thermal conductivities. Vajjha and Das [32] also agreed that thermal conductivity is dependent not only on the nanoparticles concentration but also on the temperature. Authors concluded that, it will be more beneficial if nanofluids are used in high temperature applications.

There are few reports on $\mathrm{SiC}, \mathrm{CeO}_{2}$, and $\mathrm{SiO}_{2}$ nanoparticles reinforcing conventional fluids that confirmed significant decrease on the efficiency of thermal conductivity with respect to increase in particle shapes or sizes [33-42]. Table 2, Illustrates a summary in enhancement of thermal conductivity of nanoparticles 
Table 2; Review on the Enhancement of Thermal Conductivity of Nanoparticles

\begin{tabular}{|c|c|c|c|c|c|}
\hline $\begin{array}{l}\text { Nanop } \\
\text { articles }\end{array}$ & $\begin{array}{l}\text { Base } \\
\text { fluids }\end{array}$ & $\begin{array}{l}\text { Temperatur } \\
\text { e/Morpholo } \\
\text { gy }\end{array}$ & $\begin{array}{l}\text { Concentr } \\
\text { ation }(\%)\end{array}$ & $\begin{array}{c}\mathrm{TC} \\
\text { Enhanc } \\
\text { ement } \\
(\%)\end{array}$ & $\begin{array}{c}\text { Refere } \\
\text { nce }\end{array}$ \\
\hline $\mathrm{Cu}$ & EG & & $0.3 \mathrm{wt} \%$ & 40 & [43] \\
\hline $\mathrm{Al}_{2} \mathrm{O}_{3}$ & Water & $\begin{array}{c}\text { Brick } \\
20 * 40 * 40 \\
\mathrm{~nm} \\
\end{array}$ & $7 \mathrm{wt} \%$ & 16 & [44] \\
\hline $\mathrm{Al}_{2} \mathrm{O}_{3}$ & EG & $24-50{ }^{\circ} \mathrm{C}$ & $0.2-5 \%$ & 40 & [45] \\
\hline $\begin{array}{c}\text { MWC } \\
\text { NT }\end{array}$ & Water & $25-55^{\circ} \mathrm{C}$ & $0.05-1$ & 45 & [46] \\
\hline $\begin{array}{c}\text { Diamo } \\
\text { nd }\end{array}$ & EG & $30,50 \mathrm{~nm}$ & $1.2 \%$ & 75 & [47] \\
\hline $\mathrm{Cu}$ & $\begin{array}{c}\text { Water } \\
\text { (laurate } \\
\text { salt as } \\
\text { dispersan } \\
\text { t) }\end{array}$ & & $0.3 \%$ & 70 & [48] \\
\hline $\mathrm{Cu}$ & Water & & 0.1 & 23.8 & [49] \\
\hline $\mathrm{MgO}$ & $\begin{array}{c}\text { Water/E } \\
\text { G }\end{array}$ & $20-50{ }^{\circ} \mathrm{C}$ & 0.1 & 34.5 & {$[50]$} \\
\hline $\mathrm{TiO}_{2}$ & Oil & $20-50^{\circ} \mathrm{C}$ & $0.1-1$ & 7.08 & [51] \\
\hline $\mathrm{GO}$ & Water & $\begin{array}{c}\text { Sheet, } 200 \text { - } \\
1000 \mathrm{~nm}\end{array}$ & $\begin{array}{l}0.01 \mathrm{wt} \% \\
0.10 \mathrm{wt} \%\end{array}$ & $\begin{array}{c}9 \\
19 \\
\end{array}$ & [52] \\
\hline GO & Water & $25-60^{\circ} \mathrm{C}$ & $\begin{array}{l}0.01- \\
0.5 \%\end{array}$ & 19.9 & [53] \\
\hline
\end{tabular}

\section{B. Viscosity property of nanofluids}

Dynamic viscosity in nanofluid is considered to be one of the important factors suitable in nanofluid pratical applications. Addition of nanoparticles helps in increasing the pumping power and viscosity of nanofluid when compared to base fluid used only. Hence, it will bring the impact to the pumping power increment. The advantages of nanofluid as heat transfer fluid are ascertained based on consideration between the increase in heat transfer performance and of pumping power [54]. Review shows that viscosity plays significant role in convective heat transfer. It then becomes a major factor responsible for drop in natural convective heat transfer of nanofluids [54]. Conventional models and experimental values are usually used in predicting the dynamic viscosity of nanofluids [55-59]. Most early studies used suspensions of millimeter or micrometer-sized particles, which led to countless problems, such as a tendency to rapidly sediment, unless flow rate is increased; not only losing the improvements in thermal conductivity, but also forming sludge sediments, increasing the thermal resistance and impairing the heat transfer capacity of the conventional fluids. Furthermore, fluids of this scale size could have considerably larger pressure drops [60-63], thus making flow through small channels much more difficult since diverse parameters are critical for device performance, such as morphology and stability of nanostructures, fluids composition, viscosity, fast sedimentation, channels clogging, erosion or wear.

\section{ENHANCING THE STABILIZATION OF NANOFLUIDS}

Water and ethylene glycol were the most conventional media in heat transfer. However, due to their relatively low thermal conductivity properties, long term stability in nanofluids, they were unable to provide the rapid convective heat transfer [3]. To improve the heat transfer conditions, modified fluids with different types of additives are used to obtain required thermodynamic parameters [64-67]. Aggregation of Nanoparticles in nanofluids results blocking of micro channels, decrease the thermal conductivity of nanofluids. This makes the study of nanofluids stability an important topic of discussion. Several studies had been carried out on the stability of nanofluids. Dispersions containing nanoparticles production of homogeneous nanofluids with high stability is still a technical challenge. In this study section, different factors that affect the stability of nanofluids are discussed.

\section{A. Surfactants}

Nanoparticles are often hydrophobic and therefore cannot typically be dispersed in most heat transfer fluids such as water or ethylene glycol without surface treatments, dispersants or surfactants [68]. The sedimentation of nanoparticles over time has been a major challenge that requires urgent attention before it widespread uptake of nanofluids. Simple methods have been proposed by researchers such as adding stabilizing agents (surfactants) to the base fluid before the suspension of nanoparticles [69-71]

Surfactants are molecular modifier in enhancing the surface of suspended particles in the liquid media. Proper application of right surfactant prevents nanoparticles agglomeration/sedimentation and clogging of nanoparticles. Surfactants or dispersion agents are therefore commonly used in nanofluids. Although they are beneficial for stabilizing the suspension, they may also create certain problems for heat transfer mediums. Nanoparticles agglomeration increases as filler fraction increases, due to closer particles and higher Van der Waals attraction. Similarly, this issue generates other problems such as viscosity increments [72]

\section{B. Ultra-sonication, Milling}

Separation of agglomerated particles from the mixture can be made a reality by the use of devices such as: sol-gel and vapour phase methods, ultrasonic cleaners (both bath and the probe type), ball mills, magnetic and high-speed stirrers with a high shear coefficient, high-pressure homogenizers and high shear homogenizers [72]. During the ultra-sonication process, there is significant disintegration of larger particles into minute particles due to the supersonic waves. At longer ultrasonication time, particles are further disintegrated to reasonable smaller sized particles and exhibits better stability [73]. 


\subsection{The Stability Evaluation Methods for Nanofluids}

\section{A. Sedimentation/Centrifugation Methods.}

Several approaches had been made to evaluate the stability of nanofluids. One of the easier methods is sedimentation/centrifugation method [74]. The sediment weight or volume of nanoparticles in a nano base-fluid under the influence of an external force field is a vivid indication that the stability of the characterized nanofluid is achieved. The nanofluids are considered stable when the nano-sized particles or its corresponding concentration of supernatant particles are kept constant.

\section{B. Zeta Potential Analysis.}

Zeta potential is electric potential in the interfacial double layer at the location of the slipping plane versus a point in the bulk fluid away from the interface, and it shows the potential difference between the dispersion medium and the stationary layer of fluid attached to the dispersed particle [75]. The importance of zeta potential is that its end-value can be related to the stability of colloidal dispersions. This entails that, colloids with high values of zeta potential (either negative or positive) are say to be electrically stable and vice versa. Zhu et al. [75] measured the zeta potential of $\mathrm{Al}_{2} \mathrm{O}_{3}-\mathrm{H}_{2} \mathrm{O}$ nanofluids under different $\mathrm{pH}$ values and different SDBS concentration. The Derjaguin Laudau Verwey Overbeek (DLVO) theory was used to calculate attractive and repulsive potentials.

\section{Spectral Absorbency Analysis.}

Spectral absorbency analysis is one of the most efficient means in evaluating the stability of nanofluids. Generally, there is a mutual link between the absorbency intensity and concentration of nanoparticles in fluid [72,73]. Huang et al. [76] evaluated the dispersion characteristics of alumina and copper suspensions using the conventional sedimentation method with the help of absorbency analysis by using a spectrophotometer after the suspensions deposited for $24 \mathrm{~h}$.

\subsection{Characterization Techniques}

The following approaches are adopted to characterize the distribution and particle size of molecules in a nanofluid, following its stabilization stage:

(1) Dynamic light scattering (DLS) distribution method also known as photon correlation spectroscopy (PCS) or quasi-elastic light scattering; It is used to determine the hydrodynamic size of nanoparticles and their respective agglomeration level in a solution with function to time.

(2) Scanning electron microscopy (SEM) and transmission electron microscopy (TEM0 images. SEM is use to study the micro structure and morphology of nanoparticles or nanostructured materials while TEM is similar to SEM but it has much higher resolution than that of SEM.
(3) X-ray diffraction (XRD); Images taken by XRD are highly useful in identifying and studying the crystal behaviour of nanoparticles.

(4) FT-IR (Fourier-Transform Infrared Spectroscopy) is use to study the surface chemistry of solid particles and solid-liquid particles.

(5) TGA (Thermo-gravimetric Analysis) is used to study the effect of heat transfer on the thermal stabilities of nanoparticles.

\section{OVERVIEW OF VARIOUS APPLICATIONS OF NANOFLUIDS}

\section{A. Application in chillers}

Several reports shows that $40 \%$ increase in thermal conductivity for $0.4 \%$ volume fraction of nanofluids results in enhancing the performance of chillers in air conditioning systems [2].

\section{B. Nanofluids in cameras and microdevices}

Study by Tasciuc $[2,77]$ demonstrated innovative ability by proving that nanofluids show enhanced performance and stability when exposed to electric fields, which could lead to new types of miniature camera lenses, cell phone displays, and other micro-scale fluidic devices.

\section{Nanofluid in Detecting knock occurrence in a gas SI engine}

Olivier et al. [78] numerically examined $5 \%$ water $/ \mathrm{Al}_{2} \mathrm{O}_{3}$ nanofluids. Results show that the use of the nanofluids leads to increased thermal signal variations by around $15 \%$ over water.

\section{Nanofluids as coolant in machining}

Heat transfer and its corresponding friction associated with the cutting and machining process had in decades pose a challenge in terms of tool life. Several conventional cutting fluids (vegetable oils, mineral oils) have been used in addressing the problem. However, their inability to maximally dissipate heat, provide adequate lubrication and environmental hazards posed by these fluids have limited their usage. In view of the above challenges, nanofluids have gained renewed interest. Nanofluids, with their cooling and lubricating properties, have emerged as a promising solution [79]

\section{E. Nanofluids used as heat treatment of materials}

Nanofluids have been considered for vast areas of applications as assortment and the multifaceted nature of the nanofluid frameworks, no understanding has been consummated on the particle-size of most potential advantages of utilizing nanofluids for heat transfer applications [80]. Safaa M et al. [80] concentrated their research on new additive for water quenching media for medium carbon steel (CK45). The $\mathrm{ZnO}$ nanoparticles shows significant effects on cooling rate by promoting the cooling rate at $1 \mathrm{wt} . \%$ and at $2 \mathrm{wt} . \%$ of $\mathrm{ZnO}$ nanoparticles, the emulsion promotes some of the mechanical 
properties. Devendiran et al. [81] demonstrated that the nanoparticles will enhance the heat conductivity and consequently improve heat execution of heat-transfer of the base liquid. Inamdar, M.S., et al. [82] demonstrated that nanoquenchants shows better heat transfer characteristics than conventional quenching media.

\section{F. Nano-refrigerants}

The refrigeration industry is progressively making efforts to replace traditional refrigerants with ones that have less impact on the environment. However, studies on potential replacements such as $\mathrm{R} 1234 \mathrm{ze}$ or $\mathrm{R} 1234 \mathrm{yf}$ or $\mathrm{R} 450 \mathrm{~A}$ have indicated that they yield lower heat transfer performance than the refrigerants they are intended to replace [80, 83-84].

\section{G. Solar applications}

As society makes attempts to combat climate change and also to provide sustainable energy access for all, solar energy stands out as a primary means of reducing global carbon emissions to the Earth's atmosphere [26]. Recent studies by Ebrahimnia et al. [85] demonstrated that an enhancement of $21 \%$ in average heat transfer coefficient was ascertained after conducting laminar flow convective heat transfer experiments of water-based $\mathrm{TiO}_{2}$ nanofluid flowing through a uniformly heated tube. Luo et al. [86] investigated thermal energy storage enhancement of a binary molten salt nanoparticles. They observed $4.71 \%$ enhancement of the total storage capacity at temperature range of $160-300{ }^{\circ} \mathrm{C}$. Their results also indicated an improvement in specific heat of the nano-salt by $11.48 \%$.

\section{H. Transportation}

The last decades have attest to a rapid development of automotive engine performance. Competition among engine manufacturers had grown geometrically to meet the deeming demand of their customers in producing high and efficiency engine at low cost. However, low thermal conductivity associated with the use of engine coolants limits the cooling efficiency of a vehicle radiator. In enhancing the heat transfer in an automotive car radiator, the use of new type of coolant known as "Nano-coolant" or "Nanofluid" become imperative.

Nanofluids possess better characteristics in improving cooling rate of an automotive and heavy-duty engine by increasing its efficiency, minimising the complicacy of thermal management systems and lowering the overall weight. The improved cooling rates using nanofluids for automotive engines can be maximally utilized to extricate more heat from higher power engines using same size of cooling system [88]. Ethylene glycol-based [EG] nanofluids have in present time attracted much interest in cooling automotive engines [89-90] due to its outstanding low-pressure operational characteristic compared with a 50/50 mixture of EG and water, which is universally accepted as automotive coolant. The nanofluids also exhibits high boiling point, and can be used to optimize the normal coolant operating temperature and then eject more heat easily.
Kole et al. [91] demonstrated the use of $\mathrm{Al}_{2} \mathrm{O}_{3}$ nanofluid in preparing automotive engine coolant using a standard car engine coolant (HP KOOLGARD) as the base fluid. A comprehensive study was carried out on the thermal conductivity and viscosity of the coolant using $3.5 \%$ volume fraction of $\mathrm{Al}_{2} \mathrm{O}_{3}$ nanoparticles. Results show a slight increase in thermal conductivity than the base fluid and a maximum enhancement of $10.41 \%$ was recorded at room temperature. Tzeng et al. prepared a coolant for cooling automatic transmission engine by dispersing a $\mathrm{CuO}$ and $\mathrm{Al}_{2} \mathrm{O}_{3}$ nanoparticle into a based fluid (engine oil) [92]. The results showed that $\mathrm{CuO}$ nanofluids exhibit lower transmission temperatures both at high and low rotating speeds and vice versa. Such results are encouraging for improving heat transfer rates in automotive systems using nanofluids. The recent experimental analysis carried out on a vehicle cooling system was demonstrated by Ali et al [93]. They evaluated the characteristics of convectional heat transfer in Toyota Yaris radiator filled with $\mathrm{Al}_{2} \mathrm{O}_{3}$-water nanofluid. Result shows that the heat transfer coefficient reaches its optimum at maximum volume fraction of $1 \%$. Further increase in the volume fraction would deteriorate the performance of the radiator cooling system.

\section{Space and Military}

Space and military defence are regarded as an important sector of a country that requires the highest reliability and functionality of equipment under extreme operating conditions. In such applications, failure of the equipment can result to a substantial financial loss or become dangerous to human lives. Therefore, it becomes necessary for such equipment to show better performance under all working conditions [72]. Some important factors such as energy consumption, weight of aircraft in space station, makes it important for a high demand for high efficient cooling system with smaller size. A great number of military components, devices and systems require high-heat flux. At this level, the cooling of military components is vital for a reliable and efficient operation. Nanofluids with better heat fluxes have the potential to provide the required cooling in such applications as well as in other military systems, including military vehicles, submarines, and high-power laser diodes. Therefore, nanofluids have wide application in space and defence fields, where power density is very high and the components should be smaller and weight less [72].

\section{J. Energy Applications}

For maxima utilization of nanofluids for energy applications, two remarkable properties of nanofluids are employed. Firstly, is the ability of nanofluids to rapidly absorb heat from the system and secondly, the thermal conductivities of nanofluids.

The inter-connectivity between energy source and energy demands had necessitate the development of energy storage system. Storage of thermal energy in the form of latent heat has in recent decade become an important area of energy management. It's one of the most efficient means of storing 
thermal energy. Wu et al. [95] investigated the potential of $\mathrm{Al}_{2} \mathrm{O}_{3}-\mathrm{H}_{2} \mathrm{O}$ nanofluids as a new phase change material (PCMs) for thermal energy storage. Results shows that further addition of $\mathrm{Al}_{2} \mathrm{O}_{3}$ nanoparticles decreases the super-cooling intensity of water, advanced the initial freezing time and reduced the total freezing time. Liu et al. [96] prepared a new form of nanofluid phase change materials (PCMs) by suspending a little quantity of $\mathrm{TiO}_{2}$ nanoparticles in saturated $\mathrm{BaCl}_{2}$ aqueous solution. The new form of nanofluids PCMs is said to exhibit high thermal conductivities when compared to the base material. Copper nanoparticles were used as surfactant to improve the heating and cooling rates of PCMs.

\section{K. Magnetic Sealing}

A nanoparticle in nanofluids tends to create a protective film with low elastic modulus and hardness on the worn surface can be regarded as the chief reason that some nanofluids exhibit excellent lubricating properties. Magnetic fluids (ferromagnetic fluid) are special nanofluids that rotary seals easily with no maintenance, low leakages and have vast range of applications. It utilizes the magnetic properties of the magnetic nanoparticles in liquid. Due to its stability in colloidal suspensions of small magnetic particles such as magnetite $\left(\mathrm{Fe}_{3} \mathrm{O}_{4}\right)$, its magnetic component of magnetic nanofluids may be channelled by varying their size and adapting their surface coating in order to meet the requirements of colloidal stability of magnetic nanofluids with nonpolar and polar carrier liquids [87,94]. Magnetic sealing offers a cost-effective and lasting solution to hazardous-gas sealing and environment in a vast variety of industrial equipment with high capability, low-friction power losses, long life spam and high reliability when compare to mechanical sealing. Mitamura et al. [97] evaluated the use of a magnetic fluid seal to rotary blood pumps. The developed magnetic fluid seal worked continuously for 286 days in a flow condition, 24 days in a pulsatile flow condition and $24 \mathrm{~h}$ (electively terminated) in blood flow [97]. Ferro-cobalt magnetic fluid was used for oil sealing, and the holding pressure is 25 times higher than that of a conventional magnetite sealing [98].

\section{Intensify Micro-reactors}

The discovery of high heat transfer enhancement in nanofluids can be applicable to the area of chemical reactors through the heat transfer in compact multifunctional reactors. Fan et al. examined a $\mathrm{TiO}_{2}$ nanofluid dispersed in EG in an integrated reactor-heat exchanger [99]. The overall heat transfer coefficient shows remarkable increase of $35 \%$ in a steady state continuous experiment.

\section{Nanofluids as Vehicular Brake Fluids}

The process of braking in automotive is known to disperse kinetic energy through heat and this is also transmitted throughout the brake fluid in the enclosed hydraulic brake system. In recent decade, there is a growing demand of efficient brake fluids. Copper-oxide and aluminium-oxide based brake nanofluids are proven to possess good brake fluids properties [100-101].

\section{CHALLENGES USING NANOFLUIDS}

Many attractive properties exhibited by the use of nanofluids have been affirmed and reported in the review by researchers. The use of nanofluids in a wide variety of applications appears to have future prospects. But the growth of this field is impede by dis-census of results among researchers; poor characterization of suspensions of various nanofluids; insufficient theoretical knowledge on the mechanisms that is so responsible for changes in fluid properties. Therefore, this section of the study summarizes important issues that should receive more attention in the near future. Issues, such as thermal conductivity, particle migration, Brownian motion of particles, and thermo-physical property change with temperature, must be critically considered with convective heat transfer in nanofluids. The use of nanofluids in heat pipes has shown improvement in fluid performance and a significant reduction in thermal resistance. However, recent studies indicate particle clogging in micro-channel heat sinks. Further study is required in this area to identify reason(s) for and the effects of particle deposition.

\section{A. Long term stability of nanoparticles dispersion}

The preparation of homogeneous suspension had been a technical challenge due to strong van der Waals force of interactions that exist between the particles, resulting to clogging of nanoparticles.

Generally, long term stability of nanoparticles dispersion is one of the basic features required for effective and efficient nanofluids applications. Nanofluids stability with better dispersion characteristics shows higher thermal conductivity of the nanofluids $[2,102]$. However, the dispersion behaviour of nanoparticles could be greatly

Influenced with time. Eastman et al. [103] demonstrated that thermal conductivity of EG-based nanofluids containing 0.3 $\%$ copper nanoparticles decreases with time. Result shows that fresh nanofluids exhibits slight increase in thermal conductivities compared to nanofluids that were stored for months. This may be attributed to reduction in dispersion stability of nanoparticles with respect to time.

\section{B. Higher viscosity}

The viscosity of nanoparticle-water suspensions increases accordingly with increasing particle concentration in the suspension [104]. Ahammed et al. [105] reported that viscosity and surface tension of graphene-water nanofluid is greatly influenced by the volume concentration and temperature. 


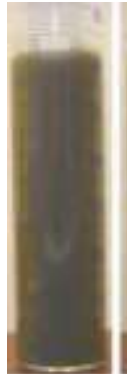

(a)

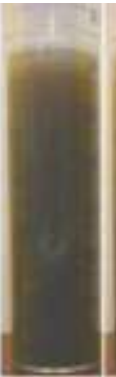

(b)

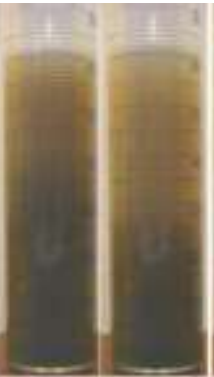

(c)

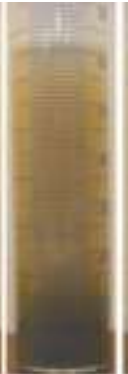

(e)

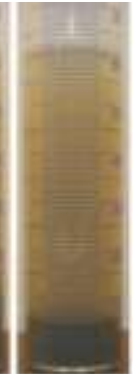

(f)

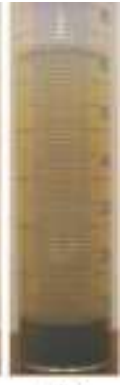

(a)
Fig. 2: The sedimentation of diamond nanoparticles at settling times of (a) 0 min, (b) $1 \mathrm{~min}$, (c) $2 \mathrm{~min}$, (d) $3 \mathrm{~min}$, (e) $4 \mathrm{~min}$, (f) $5 \mathrm{~min}$, and (g) $6 \mathrm{~min} \mathrm{[103]}$

\section{High cost of nanofluids}

Higher production cost of nanofluids is one the major factors that hamper the maxima use of nanofluids in industry. Nanofluids can be produced by either one step or two steps methods, but researchers had come up with innovative methods of producing nanofluids. However, these methods require advanced and sophisticated equipment.

\section{Increased pumping power}

A drop in pressure during the process of coolant flow is one of the important factors that determine the efficiency of nanofluids application. The drop in pressure can be influenced by the density and viscosity of the fluids. Coolants with higher density and viscosity exhibits higher pressure drop and vice versa [106-107].

\section{Difficulties in production process}

Reviews shows that there are two commonly known methods employed in the preparation of nanofluids namely; single-step approach that concurrently produce and disperses the nanoparticles into the required base fluids, or a two-step method that entails to generate nanoparticles and subsequently dispersing it into the desired base fluid. Both production approaches involve either the reduction reactions or ion exchange. Ions and reaction products contained in the base fluids makes it difficult or nearly impossible to separate from the fluids. Another challenges encountered during the process is the tendency of nanoparticles to agglomerate into larger particles. This limits the advantages of the high surface area using nanoparticles.

\section{CONCLUSIONS}

This work focused on the chronology, synthesis, characterization and the stability of various nanofluids. However, further research is necessary for better understanding of nanofluids. Nanofluids, in decades have displayed numerous interesting potential applications but some major challenges faced with the use of it mitigate the maxima application of the fluid.

\section{FUTURE WORK}

The following salient issues should receive keen attention in the nearest future. Firstly, further experimental and theoretical research is necessary to ascertain the cogent factors influencing the performance of nanofluids. Experimental and theoretical results from various researchers lack congeniality. Detailed and correct structural characterization of the suspensions may be the hidden key to unfold the discrepancy in the experimental data. Secondary, viscosity increase in nanofluids is a major set-back that is associated with increased pumping power. Nanofluids with low viscosity are highly recommended. Optimizing the compatibility between base fluids and nano materials by modifying the interface properties of two phases may be a way out. Thirdly, the particle size, shape in nanofluids are important properties; the need for brand new nanofluid synthesis approaches with simplify controllable microscope structure will be interesting. Fourthly, nanofluids stability is a crucial key for both research and practical applications. This should be given paramount research attentions. Lastly, there are little or undetailed investigation on the thermal performance of nanofluids at high temperatures. This may widen the scope of nanofluids with respect to its application as similarly discovered in high solar energy absorption and high-temperature energy storage. High temperature may expedite the degradation of surfactants used as dispersants in nanofluids. In addition to these fundamental issues, there are need to also address a number of major concerns related with the use of nanofluids, including corrosion, compatibility, clogging, abrasion and long-term stability.

\section{REFERENCE(S)}

[1] Tayyab Raza Shah, Hafiz Muhammad Ali. Applications of hybrid nanofluids in solar energy, practical limitations and challenges: A critical review, Solar Energy 183 (2019) pp173-203

[2] R. Saidur, K.Y.Leong, H.A.Mohammad (2011). A Review on Applications and Challenges of Nanofluids. Renewable and Sustainable Energy Reviews 15 pp1646-1668

[3] Sylwia Wci'slik. Review, Efficient Stabilization of Mono and Hybrid Nanofluids, Energies 2020, 3793; doi:10.3390/en 13153793

[4] Taniguchi, N. On the basic concept of "nano-technology". In Proceedings of the International Conference on Production Engineering, Tokyo, Japan, 26-29 August 1974; Volume 5, Part II. pp. 8-23.

[5] L.S. Sundar, G.O. Irurueta, E. Venkata Ramana, M.K. Singh, A.C.M. Sousa, Thermal conductivity and viscosity of hybrid nanfluids prepared with magnetic nanodiamond-cobalt oxide $\left(\mathrm{ND}-\mathrm{CO}_{3} \mathrm{O}_{4}\right)$ nanocomposite, Case Study. Therm. Eng. 7 (2016) 66-77.

[6] Bozorth, R.M. Ferromagnetism; Wiley-IEEE Press: New York, NY, USA, 1951; Van Nostrand

[7] Akoh, H.; Tsukasaki, Y.; Yatsuya, S.; Tasaki, A. Magnetic properties of ferromagnetic ultrafine particles prepared. J. Cryst. Growth 1978, 45, 495-500

[8] Brown, D.P.; Chung, J.N.; Crowe, C.T. A numerical simulation of nanocluster formation in supersonic expansion flows. Micromechanical Syst. 1992, 40, 211-225.

[9] Choi, U.S.; Eastman, J.A. Enhancing thermal conductivity of fluids with nanoparticles, Developments and Applications of NonNewtonian Flows. J. Heat Transf. 1995, 66, 99-105.

[10] Amir Kakavandi, Mohammad Akbari. Experimental investigation of thermal conductivity of nanofluids containing of hybrid nanoparticles suspended in binary base fluids and propose a new correlation, International Journal of Heat and Mass Transfer 124 (2018) 742-751 
[11] Nikhil S. Nagulkar, Dr. S. M. Lawankar. Study of Properties of Nanofluids and its Effect. International Research Journal of Engineering and Technology (IRJET) Volume: 04 Issue 06 June, 2017

[12] Wongwises S, Duangthongsuk W (2010). An experimental study on the heat transfer performance and pressure drop of $\mathrm{TiO}_{2}$-water nanofluids flowing under a turbulent flow regime. Int J Heat Mass Transfer 53:334-344

[13] Hamed Eshgarf, Rasool Kalbasi, Akbar Maleki, Mostafa Safdari Shadloo, Arash karimipour. A review on the properties, preparation, models and stability of hybrid nanofluids to optimize energy consumption. Journal of Thermal Analysis and Calorimetry 2020, 151 https://doi.org/10.1007/s10973-020-09998$\mathrm{w}$

[14] Nirupama Patra, Vivek Gupta, Ravi Singh, R.S. Singh, Pradyumna Ghosh, Arun Nayak. An experimental analysis of quenching of continuously heated vertical rod with aqueous $\mathrm{Al}_{2} \mathrm{O}_{3}$ nanofluid. Resource-Efficient Technologies 3 (2017) 378-384

[15] G. Paul , P.K. Das , I. Manna, Rewetting of vertical pipes by bottom flooding using nanofluid as a coolant, J. Heat Transfer 137 (2015) 121009

[16] G. Paul , P.K. Das , I. Manna , Assessment of the process of boiling heat transfer during rewetting of a vertical tube bottom flooded by alumina nanofluid, Int. J. Heat Mass Transf 94 (2016) 390-402.

[17] S.S. Yahya, S. Harjanto, W.N. Putra, G. Ramahdita, Kresnodrianto,E.P. Mahiswara (2018). Characterization and Observation of Water-based Nanofluids Quench Medium with Carbon Particle Content Variation, Proceedings of the International Seminar on Metallurgy and Materials (ISMM2017). Cite as: AIP Conference Proceedings 1964, 020006; https://doi.org/10.1063/1.5038288

[18] Caio Carvalho dos Santosa, Wesley Renato Vialia, Eloiza da Silva Nunesa, Douglas Ricardo de Assisa, Bruno Estevan Amantéaa, Miguel Jafelicci Júnior (2017). Aqueous Nanofluids Based on Copper MPA: Synthesis and Characterization, Materials Research; 20(Suppl. 1): 104-110. DOI: http://dx.doi.org/10.1590/1980-5373-MR-2017-0309

[19] Amir Arya, Saeed Shahmiry, Vahid Nikkhah, Mohamad Mohsen Sarafraz (2017). Cooling Of High Heat Flux Flat Surface with Nanofluid Assisted Convective Loop: Experimental Assessment. Archive of Mechanical Engineering. Vol. LXIV, no.4. DOI: 10.1515/meceng-2017-0030

[20] M.M. Sarafraz, A. Arya, F. Hormozi, andV. Nikkhah (2017). On the convective thermal performance of a CPU cooler working with liquid gallium and $\mathrm{CuO} /$ water nanofluid: A comparative study. Applied Thermal Engineering, 112:1373-1381, doi: 10.1016/j.applthermaleng.2016.10.196.

[21] S.E. Ghasemi, A.A. Ranjbar, and M.J. Hosseini (2017). Experimental and numerical investigation of circular minichannel heat sinks with various hydraulic diameter for electronic cooling application. Microelectronics Reliability, 73:97-105.doi: 10.1016/j.microrel.2017.04.028.

[22] S.E. Ghasemi, A.A. Ranjbar, and M.J. Hosseini (2017). Forced convective heat transfer of nanofluid as a coolant flowing through a heat sink: Experimental and numerical study. Journal of Molecular Liquids, 248:264-270. doi: 10.1016/j.molliq.2017.10.062.

[23] Hassanen Jaber,Tunde Kovacs, László TÓTH (2019). Effects of Water/TiO 2 Nano-Fluid Quenching Media on Microstructure and Properties of CK35 Steel. European Journal of Materials Science and Engineering. Volume 4, Issue 2, 92 - 100. DOI:10.36868/ejmse.2019.04.02.092

[24] Rakesh K. Bumataria, N.K. Chavda, Hitesh Panchal, Current research aspects in mono and hybrid nanofluid based heat pipe technologies, Heliyon 5 (2019) e01627

[25] Liu Yang and Yuhan Hu (2017). Toward TiO2 Nanofluids—Part 2: Applications and Challenges, Nanoscale Research Letters 12:446. DOI: 10.1186/s11671-017-2185-7

[26] Abdul Kaggwa and James K. Carson (2019). Developments and future insights of using nanofluids for heat transfer enhancements in thermal systems: a review of recent literature. International Nano Letters. Doi: https://doi.org/10.1007/s40089019-00281-x

[27] Munish Gupta, Vinay Singh, Satish Kumar, Sandeep Kumar, Neeraj Dilbaghi, Zafar Said (2018). Up to Date Review on the Synthesis And Thermophysical Properties of Hybrid Nanofluids. Journal of Cleaner Production, 190,169192. https://doi.org/10.1016/j.jclepro.2018.04.146

[28] Lee, S.L., Saidur, R., Sabri, M.F.M., Min, T.K (2016). Effects of the particle size and temperature on the efficiency of nanofluids using molecular dynamic simulation. Numer. Heat Transf. A Appl. 69, 996-1013. https ://doi.org/10.1080/10407782.2015.1109369

[29] Ueki, Y., Aoki, T., Ueda, K., Shibahara, M (2017). Thermophysical properties of carbon-based material nanofluid. Int. J. Heat Mass Transf. 113, 1130-1134 Doi: https://doi.org/10.1016/j.ijheatmasstrans fer.2017.06.008

[30] Deepak Selvakumar, R., Dhinakaran, S. (2016). A multi-level homogenization model for thermal conductivity of nanofluids based on particle size distribution (PSD) analysis. Powder Technol. 301, 310-317. https ://doi.org/10.1016/j.powtec.2016.05.049

[31] Lenin, R., Joy, P.A.: Studies on the role of unsaturation in the fatty acid surfactant molecule on the thermal conductivity of magnetite nanofluids. J. Colloid Interface Sci. 506, 162-168 (2017). Doi: https://doi.org/10.1016/j.jcis.2017.07.038

[32] Vajjha RS, Das DK. Experimental determination of thermal conductivity of three nanofluids and development of new correlations. Int J Heat Mass Transfer, 2009;52:4675-82.

[33] Raja M, Vijayan R, Dineshkumar P, Venkatesan M. Review on nanofluids characterization, heat transfer characteristics and applications. Renewable and Sustainable Energy Reviews. 2016;64:163-173. doi: 10.1016/j.rser.2016.05.079

[34] Suresh T, Uthayakumar G, Srinivasan R. Synthesis and characterization of $\mathrm{CeO} 2 /$ water nanofluids and its thermal properties. 2016 International Conference on Energy Efficient Technologies for Sustainability (ICEETS). IEEE; 2016. p. 202205. doi: 10.1109/ICEETS.2016.7582926

[35] Sharafeldin MA, Gróf G. Experimental investigation of flat plate solar collector using $\mathrm{CeO} 2$-water nanofluid. Energy Conversion and Management. 2018;155:32-41. DOI: https://doi.org/10.1016/j.enconman.2017.10.070

[36] Amiri M, Movahedirad S, Manteghi F. Thermal conductivity of water and ethylene glycol nanofluids containing new modified surface $\mathrm{SiO}_{2}-\mathrm{Cu}$ nanoparticles: Experimental and modeling. Applied Thermal Engineering. 2016;108:48-53. DOI: 10.1016/j.applthermaleng.2016.07.091

[37] Abdolbaqi MK, Sidik NAC, Rahim MFA, Mamat R, Azmi WH, Yazid MNAWM, Najafi G. Experimental investigation and development of new correlation for thermal conductivity and viscosity of $\mathrm{BioGlycol} /$ water based $\mathrm{SiO}_{2}$ nanofluids. International Communications in Heat and Mass Transfer. 2016;77:54-63. DOI: 10.1016/j.icheatmasstransfer.2016.07.001

[38] Nabil MF, Azmi WH, Abdul Hamid K, Mamat R, Hagos FY. An experimental study on the thermal conductivity and dynamic viscosity of $\mathrm{TiO}_{2}-\mathrm{SiO}_{2}$ nanofluids in water:Ethylene glycol mixture. International Communications in Heat and Mass Transfer.2017;86:181-189. DOI:10.1016/j.icheatmasstransfer.2017.05.024

[39] Minea AA. Hybrid nanofluids based on $\mathrm{Al}_{2} \mathrm{O}_{3}, \mathrm{TiO} 2$ and $\mathrm{SiO}$ : Numerical evaluation of different approaches. International Journal of Heat and Mass Transfer.2017;104:852-860.DOI: 10.1016/j.ijheatmasstransfer.2016.09.012

[40] Guo Y, Zhang T, Zhang D, Wang Q. Experimental investigation of thermal and electrical conductivity of silicon oxide nanofluids in ethylene glycol/water mixture. International Journal of Heat and Mass Transfer. 2018;117:280-286.DOI: 10.1016/j.ijheatmasstransfer.2017.09.091

[41] Zhu BJ, Zhao WL, Li DD, Li JK. Effect of volume fraction and temperature on thermal conductivity of $\mathrm{SiO}_{2}$ nanofluids. Advanced 
Materials Research. 2011;306-307:1178-1181.DOI: 10.4028/www.scientific.net/AMR.306-307.1178

[42] Hossein Karimi Darvanjooghi M, Nasr Esfahany M. Experimental investigation of the effect of nanoparticle size on thermal conductivity of in-situ prepared silica-ethanol nanofluid. International Communications in Heat and Mass Transfer. 2016;77:148-154. DOI: 10.1016/j.icheatmasstransfer.2016.08.001

[43] Liu M-S, Lin MC-C, Tsai CY, Wang C-C. Enhancement of thermal conductivity with $\mathrm{Cu}$ for nanofluids using chemical reduction method. Int J Heat Mass Transfer 2006;49(17-18):302833.

[44] Kim HJ, Lee SH, Lee JH, Jang SP. Effect of Particle Shape on Suspension Stability and Thermal Conductivities of Water-based bohemite alumina nanofluids. Energy. 2015;90:1290-1297. DOI: 10.1016/j.energy.2015.06.084

[45] M.H. Esfe, A. Karimipour, W.M. Yan, M. Akbari, M.R. Safaei, M. Dahari, Experimental study on thermal conductivity of ethylene glycol based nanofluids containing $\mathrm{Al}_{2} \mathrm{O}_{3}$ nanoparticles, Int. J. Heat Mass Transf. 30 (88) (2015) 728-734.

[46] M.H. Esfe, A. Naderi, M. Akbari, M. Afrand, A. Karimipour, Evaluation of thermal conductivity of $\mathrm{COOH}-$ functionalized MWCNTs/water via temperature and solid volume fraction by using experimental data and ANN methods, J. Therm. Anal. Calorim. 121 (3) (2015) 1273-1278.

[47] Kang HU, Kim SH, Oh JM. Estimation of thermal conductivity of nanofluid using experimental effective particle volume. Exp Heat Transfer 2006;19(3):181-91.

[48] Jana S, Salehi-Khojin A, Zhong WH. Enhancement of fluid thermal conduc-tivity by the addition of single and hybrid nanoadditives. Thermochim Acta 2007;462(1-2):45-55.

[49] Liu M-S, Lin MC-C, Tsai CY, Wang C-C. Enhancement of thermal conductivity with $\mathrm{Cu}$ for nanofluids using chemical reduction method. Int $\mathbf{J}$ Heat Mass Transfer 2006;49(1718):3028-33.

[50] M.H. Esfe, M. Afrand, A. Karimipour, W.M. Yan, N. Sina, An experimental study on thermal conductivity of $\mathrm{MgO}$ nanoparticles suspended in a binary mixture of water and ethylene glycol, Int. Commun. Heat Mass Transf. 31 (67) (2015) 173-175.

[51] B. Wei, C. Zou, X. Li (2017). Experimental investigation on stability and thermal conductivity of diathermic oil based $\mathrm{TiO}_{2}$ nanofluids, Int. J. Heat Mass Transf. 31 (104) 537-543.

[52] Esfahani MR, Languri EM, Nunna MR. Effect of particle size and viscosity on thermal conductivity enhancement of graphene oxide nanofluid. International Journal of Heat and Mass Transfer. 2016;76:308-315. DOI: 10.1016/j.icheatmasstransfer.2016.06.006

[53] M.R. Esfahani, E.M. Languri, M.R. Nunna, Effect of particle size and viscosity on thermal conductivity enhancement of graphene oxide nanofluid, Int. Commun. Heat Mass Transf. 31 (76) (2016) 308-315.

[54] Diah Hidayanti Sukarno. Challenges for nanofluid applications in heat transfer technology. IOP Conf. Series: Journal of Physics: Conf. Series $795 \quad$ (2017) 012020 doi:10.1088/17426596/795/1/012020

[55] Kakac S and Pramuanjaroenkij A 2009 Int. J. Heat and Mass Transfer 52 3187-3196.

[56] Yang L, Du K, Ding YH, Cheng B and Li YJ 2012 Powder Technology 210-218.

[57] Afshin Ahmadi Nadooshan, Hamed Eshgarf, Masoud Afrand. Measuring the viscosity of $\mathrm{Fe}_{3} \mathrm{O}_{4}$-MWCNTs/EG hybrid nanofluid for evaluation of thermal efficiency: Newtonian and non-Newtonian behavior. Journal of Molecular Liquids 2018, 253 ,

169 77. https://doi.org/10.1016/j.molliq.2018.01.012

[58] K. Abdul Hamid, W.H. Azmi, M.F. Nabil, Rizalman Mamat, K.V. Sharma. Experimental investigation of thermal conductivity and dynamic viscosity on nanoparticle mixture ratios of $\mathrm{TiO}_{2}-\mathrm{SiO}_{2}$ nanofluids. International Journal of Heat and Mass Transfer 2018, 116, 1152. https://doi.org/10.1016/j.ijheatmasstransfer.2017.09.087

(143-

[59] José Jaime Taha-Tijerina, Thermal Transport and Challenges on Nanofluids Performance. http://dx.doi.org/10.5772/intechopen.72505

[60] Saraaz MM, Hormozi F. Heat transfer, pressure drop and fouling studies of multi-walled carbon nanotube nano-fluids inside a plate heat exchanger. Experimental Thermal and Fluid Science. 2016;72:1-11. DOI: 10.1016/j.expthermflusci.2015.11.004

[61] Tiwari AK, Ghosh P, Sarkar J. Performance comparison of the plate heat exchanger using different nanofluids. Experimental Thermal and Fluid Science. 2013; 49:141-151. doi: https://doi.org/10.1016/j.expthermflusci.2013.04.012

[62] Hekmatipour F, Akhavan-Behabadi MA, Sajadi B, FakoorPakdaman M. Mixed convection heat transfer and pressure drop characteristics of the copper oxide-heat transfer oil $(\mathrm{CuO}-$ HTO) nanofluid in vertical tube. Case Studies in Thermal Engineering. $\quad 2017 ; 110: 248-256 . \quad$ DOI: 10.1016/J.CSITE.2017.09.009

[63] Rostami, S.; Shahsavar, A.; Kefayati, G.; Shahsavar Goldanlou, A. Energy and exergy analysis of using turbulator in a parabolic trough solar collector filled with mesoporous silica modified with copper nanoparticles hybrid nanofluid. Energies 2020,13,2946.

[64] Efemwenkiekie U. Kelvin, Atiba E. Opemipo, Oyedepo O. Sunday. Review Of Heat Transfer Enhancement In Energy Conversion Systems; Nanotechnology. IOP Conference Series: Earth andEnvironmentalScience 2019, 331,012021. https://doi.org/10.10 88/1755-1315/331/1/012021

[65] M.F. Nabil, W.H. Azmi, K.A. Hamid, N.N.M. Zawawi, G. Priyandoko, R.Mamat. Thermo-physical properties of hybrid nanofluids and hybrid nanolubricants: A comprehensive review on performance, International Communications in Heat and Mass Transfer 83 (2017) 30-39

[66] Moloud Nourani, Nasser Hamdami, Javad Keramat, Ahmad Moheb, Mohammad Shahedi. Thermal behavior of paraffinnano-Al2O3 stabilized by sodium stearoyl lactylate as a stable phase change material with high thermal conductivity. Renewable Energy 2016, 88, 482. https://doi.org/10.1016/j.renene.2015.11.043

[67] Radomska, E.; Mika, L.; Sztekler, K. The impact of additives on the main properties of phase change materials. Energies 2020, 13, 3064.

[68] Yanping Du, Xiao Yuan. Coupled hybrid nanoparticles for improved dispersion stability of nanosuspensions: A review. Journal of Nanoparticle Research 2020, 22 (9) https://doi.org/10.1007/s11051-020-049918

[69] Aref, A.H., Entezami, A.A., Erfan-Niya, H., Zaminpayma, E.:Thermophysical properties of paraffin-based electrically insulating nanofluids containing modified graphene oxide. J. Mater. Sci. 52, 2642-2660 (2017). https ://doi.org/10.1007/s1085 3-016-0556-6

[70] Chen, W., Zou, C., Li, X., Li, L.: Experimental investigation of $\mathrm{SiC}$ nanofluids for solar distillation system: stability, optical properties and thermal conductivity with saline water-based fluid. Int. J. Heat Mass Transf. 107, 264-270 (2017). https://doi.org/10.1016/j.ijheatmass transfer.2016.11.048

[71] Yu, F., Chen, Y., Liang, X., Xu, J., Lee, C., Liang, Q., Tao, P., Deng, T.: Dispersion stability of thermal dispersion stability of thermal nanofluids. Prog. Nat. Sci. Mater. Int. 27, 531-542 (2017). https://doi.org/10.1016/j.pnsc.2017.08.010

[72] Aditya Abhang, Shashank Sonawane, Suraj Avhad Amol Kakade, B. M. Dusane. A Review on Synthesis, Mechanism and Utilization of Nanofluids. Ijarse, vol no.5 special issues no. (2), March, 2016

[73] Angela Gondolini, Elisa Mercadelli, Valentina Zin, Simona Barison, Alessandra Sanson. Easy preparation method of stable copper-based nanoparticle suspensions in lubricant engine oil. Lubrication 217. https://doi.org/10.1002/1s.1496
Science 2020, 32 (5),205- 
[74] X. Wei and L. Wang, "Synthesis and thermal conductivity of microfluidic copper nanofluids," Particuology, vol. 8, no. 3, pp. $262-271,2010$.

[75] D. Zhu, X. Li, N. Wang, X. Wang, J. Gao, and H. Li, "Dispersion behavior and thermal conductivity characteristics of $\mathrm{Al}_{2} \mathrm{O}_{3}-\mathrm{H}_{2} \mathrm{O}$ nanofluids," Current Applied Physics, vol. 9, no. 1. pp. 131-139, 2009.

[76] J. Huang, X. Wang, Q. Long, X. Wen, Y. Zhou, and L.Li, "Influence of $\mathrm{pH}$ on the stability characteristics of nanofluids," in Proceedings of the Symposium on Photonicsand Optoelectronics (SOPO ’09), 2009.

[77] Top-News.http://www.topnews.in/nanofluids-be-used-make-newtypes-cameras-microdevices-and-displays-221378;

2009 [02.11.21].

[78] Ollivier E, Bellettre J, Tazerout M, Roy GC. Detection of knock occurrence in a gas SI engine from a heat transfer analysis. Energy Convers Manage 2006;47(7-8):879-93.

[79] Srikan RR, Rao DN, Subrahmanyam MS, Vamsi KP. Applicability of cutting fluids with nanoparticle inclusion as coolants in machining. Proc IMechE Part J: Eng Tribol 2009;223.

[80] Safaa M. Hassoni, Qasim M. Azpen, Abdullah Dhayea Assi and Mustafa K. Ismael, The Role of $\mathrm{ZnO}$ Nano-fluids on Heat Treatments of Medium Carbon Steel. 3rd International Conference on Sustainable Engineering Techniques (ICSET 2020), IOP Conf. Series: Materials Science and Engineering 881 (2020) 012095. doi:10.1088/1757-899X/881/1/012095

[81] Devendiran, D.K. and V.A. Amirtham, 2016. A review on preparation, characterization, properties and applications of nanofluids. Renewable and Sustainable Energy Reviews, 60: p. 2140.

[82] Inamdar, M.S., et al., 2016. To Study the Behaviour of Materials AISI 1050, 1090, 4140 using Conventional quenching and Nano Quenching. IJETT Conf., 38(02, Aug).

[83] Kaggwa, A., Wang, C.: Investigation of thermal-hydrodynamic heat transfer performance of R- 1234ze and R-134a refrigerants in a microfin and smooth tube. J. Enhanc. Heat Transf. 23, 221239, (2016). https ://doi.org/10.1615/JEnhH eatTr ansf.20170 19585

[84] Mendoza-Miranda, J.M., Mota-Babiloni, A., Ramírez-Minguela, J.J., Muñoz-Carpio, V.D., Carrera-Rodríguez, M., NavarroEsbrí, J., Salazar-Hernández, C.: Comparative evaluation of R1234yf, R1234ze(E) and R450A as alternatives to R134a in a variable speed reciprocating compressor. Energy. 114, 753-766 (2016). https ://doi.org/10.1016/j.energ y.2016.08.050

[85] Ebrahimnia-Bajestan, E., Charjouei Moghadam, M., Niazmand, H., Daungthongsuk, W., Wongwises, S.: Experimental and numerical investigation of nanofluids heat transfer characteristics for application in solar heat exchangers. Int. J. Heat Mass Transf. 92, 1041-1052 (2016). https://doi.org/10.1016/j.ijheatmasstrans fer.2015.08.107

[86] Luo, Y., Du, X., Awad, A., Wen, D.: Thermal energy storage enhancement of a binary molten salt via in situ produced nanoparticles. Int. J. Heat Mass Transf. 104, 658-664 (2017). https://doi.org/10.1016/j.ijhea tmass trans fer.2016.09.004

[87] Wei Yu and Huaqing Xie, A Review on Nanofluids: Preparation, Stability Mechanisms, and Applications. Hindawi Publishing Corporation, Journal of Nanomaterials Volume 2012, Article ID 435873, 17 pages doi:10.1155/2012/435873

[88] W. Yu, H. Xie, L. Chen, and Y. Li, "Investigation of thermal conductivity and viscosity of ethylene glycol based $\mathrm{ZnO}$ nanofluid," Thermochimica Acta, vol. 491, no. 1-2, pp. 92-96, 2009.
[89] H. Xie and L. Chen, "Adjustable thermal conductivity in carbon nanotube nanofluids," Physics Letters Section A, vol.373, no. 21, pp. 1861-1864, 2009.

[90] M. Kole and T. K. Dey, "Thermal conductivity and viscosity of A12O3 nanofluid based on car engine coolant," Journal of Physics D, vol. 43, no. 31, Article ID 315501, 2010.

[91] S. C. Tzeng, C. W. Lin, and K. D. Huang, "Heat transfer enhancement of nanofluids in rotary blade coupling of fourwheel-drive vehicles," Acta Mechanica, vol. 179, no. 1-2, pp.11-23, 2005.

[92] M. Ali, A.M. El-Leathy, Z. Al-Sofyany, The effect of nanofluid concentration on the cooling system of vehicles radiator, Adv. Mech. Eng. (2014), 962510.

[93] Ramakoteswaa Rao .N, Leena Gahane, Ranganayakulu S.V. Synthesis, Applications and Challenges of Nanofluids - Review, IOSR Journal of Applied Physics (IOSR-JAP) pp 21-28. International Conference on Advances in Engineering \& Technology - 2014 (ICAET-2014)

[94] S. Wu, D. Zhu, X. Zhang, J. Huang, Energy Fuels 24, 1894 (2010).

[95] Y. Liu, Y. Zhou, M. Tong, X. Zhou, Microfluid. Nanofluid. 7, 579 (2009).

[96] Y. Mitamura, S. Arioka, D. Sakota, K. Sekine, and M. Azegami, "Application of a magnetic fluid seal to rotary blood pumps," Journal of Physics Condensed Matter, vol. 20, no. 20, Article ID 204145, 2008.

[97] Y. S. Kim and Y. H. Kim, "Application of ferro-cobalt magnetic fluid for oil sealing," Journal of Magnetism and Magnetic Materials, vol. 267, no. 1, pp. 105-110, 2003.

[98] X. Fan, H. Chen, Y. Ding, P. K. Plucinski, and A. A. Lapkin, "Potential of 'nanofluids' to further intensify microreactors," Green Chemistry, vol. 10, no. 6, pp. 670-677, 2008

[99] M. J. Kao, C. H. Lo, T. T. Tsung, Y. Y.Wu, C. S. Jwo, and H.M. Lin, "Copper-oxide brake nanofluid manufactured using arcsubmerged nanoparticle synthesis system," Journal of Alloysand Compounds, vol. 434-435, pp. 672-674, 2007.

[100] M. J. Kao, H. Chang, Y. Y. Wu, T. T. Tsung, and H. M. Lin, "Producing Aluminum-oxide brake nanofluids derived using plasma charging system," Journal of the Chinese Society of Mechanical Engineers, vol. 28, p. 123, 2007.

[101] Godson L, Raja, Mohan Lal D, Wongwises S. Enhancement of heat transfer using nanofluids-an overview. Renew Sust Energy Rev 2009, doi:10.1016/j.rser.2009.10.004.

[102] Wilson CA. Experimental investigation of nanofluid oscillating heat pipes. MS thesis. Columbia:University of Missouri; 2006.

[103] Dilan S. Udawattha, Mahinsasa Narayana, Uditha P.L. Wijayarathne. Predicting the effective viscosity of nanofluids based on the rheology of suspensions of solid particles. Journal of King Saud University - Science 2019, 31 (3),412426. https://doi.org/10.1016/j.jksus.2017.09.016

[104] Ahammed N., Asirvatham A.G., Wongwises S., 2016, Effect of volume concentration and temperature on viscosity and surface tension of graphene-water nanofluid for heat transfer applications, Journal of Thermal Analysis and Calorimetry, 123(2), 1399-1409, DOI: 10.1007/s10973-015-5034-x.

[105] Namburu PK, Das DK, Tanguturi KM, Vajjha RS. Numerical study of turbu- lent flow and heat transfer characteristics of nanofluids considering variable properties. Int $\mathbf{J}$ Therm Sci 2009;48:290-302.

[106] Rajesh Verma, Krishna Kumar Gupta. An insight of synthesis, stability and thermophysical properties of hybrid nanofluids. IOP Conference Series: Materials Science and Engineering 2020, 810, 012020. https://doi.org/10.1088/1757-899X/810/1/012020 